widespread dissatisfaction and a sense of frustration among students and intellectual workers generally as well as among research workers and technologists intimately associated with the war effort. Nothing short of a fully representative, detailed and documented survey can reveal the inadequacy of the present supplies. Through the good offices of the Royal Society, the Rockefeller Foundation has provided funds for the conduct of a rapid, extensive survey of this character.

The survey will be made by a Committee of the Association and will be completed by the autumn. A memorandum is being circulated to some two thousand institutions and individuals to ascertain what publications they need and the extent to which they are locally available. In the interim, endeavours will be made to facilitate the distribution of available supplies, but the primary objective is to obtain a detailed inventory of nseds and to ascertain what further supplies are essential to meet demands. Those interested should communicate with the A S L I B Foreign Periodicals Committee, 31 Museum Street, London, W.C.1.

\section{Medicinal Herbs}

THE Committee recently appointed by the Ministry of Health to consider what steps should be taken to secure organization of cultivation and collection of vegetable drugs has presented an interim report. The committee, of which the chairman is Sir Weldon Dalrymple-Champneys, considers that, so far as domestic production is concerned, attention should be concentrated on the following : Agar, dill, belladonna, Irish moss, colchicum, digitalis, ergot, male fern, liquorice, henbane, peppermint, psyllium, sphagnum, stramonium, dandelion and valerian. The committee is thus in agreement with the recommendations of the Medical Research Council, which advised, in M.R.C. War Memorandum No. 3, that all these drugs, with the exception of agar, should be produced in the United Kingdom; with regard to agar, the M.R.C. Memorandum recommended that its production should be encouraged in the British Empire overseas. Concerning the collection of herbs which grow wild, the report of the committee of the Ministry of Health states that steps have already been taken to encourage it on methodical lines, and commends the efforts of the Boy Scouts Association in this direction; the Association has circulated a pamphlet giving details of identification, methods of collecting, drying and dispatch, in respect of several vegetable drugs and has arranged that the trade will purchase the collections so made. The Royal Botanic Gardens, Kew, have conferred with the National Association of Women's Institutes to organize the collection of important herbs in each county, the selection of the herbs to be determined by their local abundance.

\section{State Laboratory of Eire}

THE report of the State Chemist of Eire upon the work of the State Laboratory for the year ending March 31, 1941, has been issued in typescript form.
The Laboratory carries out chemical work for all departments of the Government of Eire, the greater portion being performed in the Laboratory in Upper Merrion Street, Dublin, but samples of wines, spirits and tea are also examined at the chemical station in the Custom House, Cork. The total number of samples examined in the course of the year, including those dealt with at Cork, was 29,571, as compared with 37,843 in the preceding year, a decrease of 8,272 . Of this figure, 531 samples represent the decrease at Cork Chemical Station. The decrease in the number of samples examined was mainly in respect of those received for the Revenue Commissioners and the Department of Agriculture and Fisheries. There was a large fall in customs import samples, particularly in regard to wines and spirits; the fall in the number of samples received from the Department of Agriculture and Fisheries was due to the impossibility of obtaining dairy instruments from the Continent and the cessation of sea water sampling. Increases were registered in respect of 'wrecked goods', and additional samples of feeding stuffs were examined in order to control any possibility of adulteration due to shortage in supplies. The development of the Milk and Dairies (Special Designations) Regulations led to an increased number of tests being carried out for the Department of Local Government and Public Health. The introduction of the phosphatase test has enabled close control of pasteurization to be achieved; investigation of plants yielding milk failing on this test has always revealed defects corresponding to the result of the test. A variety of specimens has been examined for the Department of Justice during the year.

\section{Trichinosis in Britain}

Ar a meeting of the Section of Epidemiology and State Medicine of the Royal Society of Medicine on May 22, Dr. P. B. Beeson, of Harvard University, read a paper on factors influencing the prevalence of trichinosis in man. He said that fow cases of trichinosis have been recognized in Great Britain until recently, although the disease occurs fairly commonly in Europe and the United States. Within the past few months, however, several outbreaks have been reported in different parts of England and Wales, which have evoked a new interest in the clinical and epidemiological aspects of the disease. Since human trichinosis is nearly always acquired by eating pork, knowledge of the ways in which swine become infested is important. In the United States, where $0 \cdot 5-5 \cdot 0$ per cent of swine has trichinosis, the chief factor responsible is the practice of feeding swine on uncooked garbage. In Great Britain there is little opportunity for this means of swine infestation to take place, and the probability is that the rare cases of swine trichinosis which occur in this country are acquired by eating infested rats. Trichinosis has been found in rats in several parts of Great Britain.

Locally manufactured sausages appeared to have been the meat responsible for the recent epidemics of human trichinosis in Great Britain. In explanation of the large number of people involved in some of 